\title{
PERBANDINGAN ALGORITMA GREEDY DAN METODE BRANCH AND BOUND PADA PENYELESAIAN KNAPSACK 0-1 UNTUK MENGOPTIMALKAN MUATAN BARANG
}

\author{
D. Wungguli1 ${ }^{1}$ S. S. Ibrahim², dan L. Yahya ${ }^{3}$ \\ 1,2,3Program Studi Matematika FMIPA Universitas Negeri Gorontalo \\ JIn. Jendral Sudirman No.6, Kota Gorontalo 96128, Indonesia \\ 1septiaibrahim@gmail.com, 2lailany.yahya@ung.ac.id, 3djihad@ung.ac.id
}

\begin{abstract}
This research was conducted to determine the cargo of goods to be sold by using cargo media that has a limited capacity in obtaining maximum profit In data collection, it was required weight, profit, and maximum capacity of the truck. The calculations was done in the form of total weight and total profit of each item and then modeled into a mathematical form. The method used in this research is the greedy algorithm and the branch and bound method. Obtained several optimal solutions using the greedy algorithm, greedy by weight, greedy by profit, and greedy by density. The results show that by using the greedy algorithm, the maximum result is obtained in the greedy by profit calculation with a profit of Rp. 13952000 and a total weight of $15319 \mathrm{Kg}$. While using the branch and bound method, the profit is Rp. 141689000 with a total weight of $15599 \mathrm{Kg}$.
\end{abstract}

Keywords : Knapsack Problem 0-1, Greedy Algorithm, Branch and Bound Method

\section{ABSTRAK}

Penelitian ini dilakukan untuk menentukan muatan barang yang akan dijual dengan menggunakan media muatan yang memiliki kapasitas terbatas dalam memperoleh keuntungan maksimum. Data yang digunakan yaitu berupa berat barang, keuntungan, dan kapasitas maksimum media muatan. Selanjutnya dilakukan perhitungan berupa berat total dan keuntungan total dari setiap barang kemudian dimodelkan kedalam bentuk matematika. Metode yang digunakan dalam penelitian ini yaitu algoritma greedy dan metode branch and bound. Diperoleh beberapa solusi optimal dalam menggunakan algoritma greedy yaitu greedy by weight, greedy by profit, dan greedy by density. Hasil penilitian menunjukkan bahwa dengan menggunakan algoritma greedy diperoleh hasil yang maksimal pada perhitungan greedy by profit dengan keuntungan yaitu Rp13952000 dan berat total $15319 \mathrm{Kg}$ Sedangkan menggunakan metode branch and bound diperoleh keuntungan Rp141689000 dengan berat total $15599 \mathrm{Kg}$.

Kata kunci $\quad$ : Knapsack Problem 0-1, Algoritma Greedy, Metode Branch and Bound. 


\section{PENDAHULUAN}

Knapsack dapat diartikan sebagai karung, kantung, atau buntilan yang digunakan untuk memuat sesuatu dengan tujuan untuk mendapatkan keuntungan yang maksimum dari pemilihan objek tanpa melebihi kapasitas daya tampung media penyimpanan tersebut (Supriana, 2016). Knapsack Problem adalah suatu permasalahan optimasi dengan tujuan untuk memaksimalkan total nilai dari barang-barang yang dimasukkan kedalam wadah tanpa melewati kapasitas wadah tersebut (Kosasi, 2013). Permasalahan knapsack terdiri dari beberapa kasus yaitu integer knapsack, bounded knapsack, dan unbounded knapsack yaitu permasalahan dalam menentukan objek yang dimuat dengan kapasitas tidak terbatas (Ambarwari and Yanto, 2016). Untuk integer knapsack permasalahannya bersyarat yaitu 0 atau 1 artinya barang tersebut dimasukkan kedalam knapsack atau tidak sama sekali (Abdurrahman Rois, 2019). Menurut (Arista, 2013) terdapat beberapa persoalan optimasi dalam kehidupan sehari-hari yaitu permasalahan menentukan barang, menentukan jalur lintasan terpendek dari suatu tempat ketempat yang lain, dan menentukan jumlah pekerja seminimal mungkin untuk melakukan suatu proses produksi agar pengeluaran biaya pekerja dapat diminimalkan dan hasl produksi tetap maksimal. Dalam menentukan nilai optimum dari suatu persoalan linear dapat menggunakan metode program linear (Prasetya, 2015).

Model matematika untuk masalah knapsack terdiri dari tiga unsur yaitu variable keputusan, fungsi tujuan dan fungsi pembatas (Dimyati and Dimyati, 2018). Dalam menemukan solusi knapsack problem dapat diselesaikan dengan menggunakan metode branch and bound dan metode algoritma greedy (Rachmawati and Candra, 2013). Algoritma greedy merupakan salah satu metode popular untuk memecahkan persoalan optimasi karena akan banyak solusi kemungkinan yang ada (Sabaruddin, 2016). Cara kerja metode algoritma greedy yaitu dilakukan secara bertahap dan memperhatikan masing-masing input data pada setiap keadaan (Ammar, 2019). Metode branch and bound adalah salah satu metode untuk menyelesaikan masalah integer linear programming (Supatimah, Farida and Andriani, 2019). Sebelum melakukan perhitungan dengan menggunakan metode branch and bond terlebih dahulu menyelesaikan program linear relaksasi (Setiawani, 2017). Prinsip kerja dari metode branch and bound adalah mencabangkan variabel keputusan yang tidak memiliki penyelesaian bulat, pencabangan dilakukan terus hingga diperoleh penyelesaian bulat sehingga semua variabel keputusannya benilai bulat dan menghasilkan keuntungan maksimal pada perusahaan. Sedangkan dalam menyelesaikan knapsack problem dengan menggunakan algorima greedy terdapat beberapa beberapa jenis greedy yang dapat digunakan yaitu greedy by weight , greedy by profit, dan greedy By density.

Beberapa penelitian sebelumnya pernah menggunakan metode branch and bound dan algoritma greedy diantaranya yaitu penelitian yang dilakukan oleh (Pratiwi, Mulyono and Rochmad, 2014) pada studi kasus di sebuah CV. Pangestu Interaksi Semarang dengan menggunakan metode branch and bound dan penelitian (Ammar, 2019) untuk studi kasus sebuah jasa pengiriman PT Citra Van Titipan Kilat dengan menggunakan metode algoritma greedy. 
PK. Murni Sanjaya adalah salah satu perusahaan yang bergerak dalam bidang jual beli jenis dan bentuk kayu. PK Murni Sanjaya ini terleas di Kabupaten Gorontalo yang telah berdiri sejak tahun 2010. Sama halnya dengan perusahaan lain, perusahaan kayu Murni Sanjaya juga ingin melakukan hal yang terbaik dan tepat dalam memilih barang untuk menjamin kebutuhan bagi kelancaran usaha. Dalam menjamin kelangsungan hidup usahanya setiap perusahaan perlu menentukan masing-masing barang yang akan dijual, karenajika tidak diadakannya penentuan pemilihan barang perusahaan akan dihadapkan pada resiko bahwa suatu waktu perusahaan akan mengalami kerugian. Berdasarkan permasalahan tersebut maka dalam penelitian ini peneliti tertarik untuk menentukan solusi optimal dari permasalahan knapsack dengan menggunakan metode algoritma greedy dan metode branch and bound.

\section{METODE PENELITIAN}

Metode yang digunakan dalam penelitian ini yaitu menggunakan studi literature dengan mempelajari jurnal-jurnal dan buku serta beberapa sumber yang berkaitan dengan knapsack problem $0-1$. Langkah-langkah yang dilakukan yaitu :

1. Mengumpulkan data

2. Mendefinisikan data yang diperoleh

3. Memodelkan kedalam bentuk matematika.

4. Menerapkan perhitungan menggunakan algoritma greedy dan metode branch and bound.

5. Membandingkan solusi optimal dari berbagai solusi yang didapatkan.

6. Menentukan Solusi optimal dari kedua metode yang digunakan.

7. Representasi hasil.

\section{HASIL DAN PEMBAHASAN}

\subsection{Pendefinisian Variabel}

Dalam menyelesaikan permasalahan knapsack 0-1 dengan membandingkan metode greedy dan metode branch and bound maka diperlukan data berupa jenis kayu, berat kayu, harga jual dan harga beli di PK. Murni Sanjaya dengan kapasitas angkut maksimum dari 3 truk yang akan mengangkut kayu tersebut di PK. Murni Sanjaya sebesar 15600. Perlu dilakukan identifikasi dari data berupa berat total dan keuntungan total dari setiap barang. Untuk menentukan nilai dari berat total kayu dapat diidentifikasi dengan cara mengalikan berat dari masing-masing barang $w_{i}$ dengan banyaknya barang. Sedangkan untuk menentukan nilai dari keuntungan $v_{i}$ total dari masing-masing kayu yaitu diidentifikasi dengan cara menghitung selisih antara harga jual dengan harga beli kemudian dikalikan dengan banyaknya jumlah barang kemudian didefinisikan. 
Tabel 1 : Pendefinisian Variabel

\begin{tabular}{|c|c|c|c|c|c|c|}
\hline No & Jenis Kayu & Ukuran Kayu & $\begin{array}{l}\text { Berat Total } \\
\qquad\left(w_{i}\right) \\
\end{array}$ & $\begin{array}{c}\text { Variabel } \\
x_{i} \\
\end{array}$ & $\begin{array}{l}\text { Keuntungan Total } \\
\qquad\left(v_{i}\right)\end{array}$ & $\begin{array}{l}\text { Rasio } \\
\frac{v_{i}}{w_{i}} \\
\end{array}$ \\
\hline 1 & $\mathrm{KC}$ & $3 \times 30$ & 775 & $x_{1}$ & 1250000 & 1612.9 \\
\hline 2 & $\mathrm{KC}$ & $3 \times 20$ & 660 & $x_{2}$ & 1050000 & 1590 \\
\hline 3 & $\mathrm{KC}$ & $3 \times 25$ & 750 & $x_{3}$ & 1125000 & 1500 \\
\hline 4 & $\mathrm{KCN}$ & $3 \times 20$ & 480 & $x_{4}$ & 600000 & 1250 \\
\hline 5 & $\mathrm{KA}$ & $2 \times 25$ & 560 & $x_{5}$ & 630000 & 1125 \\
\hline 6 & $\mathrm{KC}$ & $6 \times 12$ & 630 & $x_{6}$ & 630000 & 1000 \\
\hline 7 & KM & $3 \times 5$ & 500 & $x_{7}$ & 500000 & 1000 \\
\hline 8 & $\mathrm{KC}$ & $6 \times 16$ & 840 & $x_{8}$ & 800000 & 952.38 \\
\hline 9 & $\mathrm{KM}$ & $4 \times 25$ & 640 & $x_{9}$ & 600000 & 937.5 \\
\hline 10 & $\mathrm{KCN}$ & $2.5 \times 25$ & 770 & $x_{10}$ & 700000 & 909 \\
\hline 11 & $\mathrm{KM}$ & $4 \times 5$ & 575 & $x_{11}$ & 517000 & 900 \\
\hline 12 & KM & $6 \times 16$ & 700 & $x_{12}$ & 625000 & 892.86 \\
\hline 13 & $\mathrm{KCN}$ & $2 \times 25$ & 720 & $x_{13}$ & 630000 & 875 \\
\hline 14 & KM & $5 \times 5$ & 450 & $x_{14}$ & 375000 & 833.33 \\
\hline 15 & $\mathrm{KN}$ & $2 \times 25$ & 760 & $x_{15}$ & 600000 & 789.47 \\
\hline 16 & KM & $2 \times 20$ & 605 & $x_{16}$ & 440000 & 727.27 \\
\hline 17 & $\mathrm{KA}$ & $2.5 \times 25$ & 704 & $x_{17}$ & 480000 & 681.81 \\
\hline 18 & KM & $2 \times 25$ & 675 & $x_{18}$ & 450000 & 666.67 \\
\hline 19 & KM & $5 \times 7$ & 540 & $x_{19}$ & 360000 & 666.67 \\
\hline 20 & $\mathrm{KM}$ & $6 \times 12$ & 720 & $x_{20}$ & 450000 & 625 \\
\hline 21 & KM & $2.5 \times 25$ & 648 & $x_{21}$ & 360000 & 555.55 \\
\hline 22 & $\mathrm{KN}$ & $2.5 \times 25$ & 682 & $x_{22}$ & 372000 & 545.45 \\
\hline 23 & KM & $5 \times 10$ & 570 & $x_{34}$ & 304000 & 533.33 \\
\hline 24 & $\mathrm{KM}$ & $6 \times 10$ & 650 & $x_{24}$ & 325000 & 500 \\
\hline 25 & $\mathrm{KD}$ & $6 \times 12$ & 300 & $x_{25}$ & 150000 & 500 \\
\hline 26 & $\mathrm{KM}$ & $3 \times 25$ & 400 & $x_{26}$ & 199900 & 499 \\
\hline 27 & $\mathrm{KD}$ & $3 \times 25$ & 820 & $x_{27}$ & 408000 & 498 \\
\hline 28 & $\mathrm{KM}$ & $6 \times 8$ & 125 & $x_{28}$ & 62000 & 495 \\
\hline 29 & $\mathrm{KD}$ & $6 \times 16$ & 455 & $x_{29}$ & 224000 & 492 \\
\hline 30 & $\mathrm{KM}$ & $3 \times 20$ & 120 & $x_{30}$ & 59000 & 491 \\
\hline
\end{tabular}


Pendefisian setiap barang dapat dilihat pada Tabel 1, sedangkan variabel pada knapsack problem didefinisikan sebagai :

$$
x_{i}=\left\{\begin{array}{l}
1, \text { jika barang ke }- \text { dimasukkan kedalam truk } \\
0, \text { jika barang ke }- \text { i tidak dimasukkan kedalam truk }
\end{array} \quad \forall i=1,2,3, \cdots, 30\right.
$$

Permasalahan knapsack dapat dimodelkan kedalam bentuk matematika sehingga memperoleh fungsi tujuan dan fungsi pembatas untuk memaksimumkan keuntungan.

Fungsi Tujuan :

Maksimumkan :

$$
\begin{aligned}
Z= & 1250 x_{1}+1050 x_{2}+1125 x_{3}+600 x_{4}+630 x_{5}+630 x_{6}+500 x_{7}+800 x_{8}+ \\
& 600 x_{9}+700 x_{10}+517 x_{11}+625 x_{12}+630 x_{13}+375 x_{14}+600 x_{15}+440 x_{16}+ \\
& 480 x_{17}+450 x_{18}+360 x_{19}+450 x_{20}+360 x_{21}+372 x_{22}+304 x_{23}+325 x_{24}+ \\
& 150 x_{25}+199.9 x_{26}+408 x_{27}+62 x_{28}++224 x_{29}+59 x_{30}
\end{aligned}
$$

Fungsi Pembatas :

$$
\begin{aligned}
& 775 x_{1}+660 x_{2}+750 x_{3}+480 x_{4}+560 x_{5}+560 x_{6}+500 x_{7}+840 x_{8}+640 x_{9}+ \\
& 770 x_{10}+575 x_{11}+700 x_{12}+720 x_{13}+450 x_{14}+760 x_{15}+605 x_{16}+704 x_{17}+ \\
& 675 x_{18}+540 x_{19}+720 x_{20}+648 x_{21}+682 x_{22}+570 x_{23}+650 x_{24}+300 x_{25}+ \\
& 400 x_{26}+820 x_{27}+125 x_{28}+455 x_{29}+120 x_{30} \leq 15600 \\
& x_{i} \geq 0 \text { untuk } i=1,2,3, \cdots, 30 .
\end{aligned}
$$

\subsection{Perhitungan Algoritma Greedy}

Perhitungan algoritma greedy terdapat 3 strategi greedy yang akan digunakan untuk menentukan barang yang akan dipilih untuk dimasukkan kedalam knapsack yaitu greedy by weight, greedy by profit, dan greedy by density (Supriadi, 2016).

\subsubsection{Greedy by weight}

Greedy by weight adalah mengurutkan barang pada Tabel 1 berdasarkan berat teringan kemudian dimasukkan satu persatu barang kedalam truk dengan kapasitas truk sebesar $15600 \mathrm{Kg}$ sampai kapasitas truk penuh atau sudah tidak ada lagi yang bisa dimasukkan. Menurut perhitungan dengan menggunakan strategi greedy by weight barang yang akan dimasukkan kedalam truk yang bernilai 1 yaitu $\left\{x_{2}, x_{3}, x_{4}, x_{5}, x_{6}, x_{7}, x_{9}, x_{10}, x_{11}, x_{12}, x_{13}, x_{14}, x_{15}, x_{16}, x_{17}\right.$ $\left.x_{18}, x_{19}, x_{20}, x_{21}, x_{22}, x_{23}, x_{24} x_{25}, x_{26}, x_{28}, x_{29}, x_{30}\right\}$ sedangkan untuk $\left\{x_{1}, x_{8}, x_{27}\right\}$ bernilai 0 karena apabila ketiga barang tersebut dimasukkan maka akan melebihi kapasitas truk. Menurut perhitungan greedy by weight diperoleh solusi optimal yaitu $X=\{0,1,1,1,1,1,1,0,1,1,1,1,1,1,1$, $1,1,1,1,1,1,1,1,1,1,1,0,1,1,1\}$. Berdasarkan fungsi tujuan pada Persamaan (1) maka keuntungan yang diperoleh dari perhitungan greedy by weight dengan total berat barang yang diangkut sebesar $15389 \mathrm{Kg}$ yaitu Rp.12817900. 


\subsubsection{Greedy by profit}

Greedy by profit adalah mengurutkan barang-barang pada Tabel 1 berdasarkan keuntungan terbesar dengan tetap memperhatikan berat barang kemudian dimasukkan satu persatu barang kedalam truk sampai kapasitas truk penuh atau sudah tidak ada lagi yang bisa dimasukkan. pada perhitungan dengan menggunakan strategi greedy by profit barang yang akan dimasukkan kedalam truk yang bernilai 1 yaitu $\left\{x_{1}, x_{2}, x_{3}, x_{4}, x_{5}, x_{6}, x_{7}, x_{8}, x_{9}, x_{10}, x_{11}, x_{12}, x_{13}, x_{14}, x_{15}, x_{16}, x_{17}, x_{18}, x_{19}, x_{20}, x_{21}, x_{22}, x_{27}\right\}$ sedangkan untuk $\left\{x_{23}, x_{24}, x_{25}, x_{26}, x_{28}, x_{29}, x_{30},\right\}$ bernilai 0 karena apabila ketiga barang tersebut dimasukkan maka akan melebihi kapasitas truk. Menurut perhitungan greedy by profit diperoleh solusi optimal yaitu $X=\{1,1,1,1,1,1,1,1,1,1,1,1,1,1,1,1,1,1,1,1,1,1,1,1,0,0,0,0,0,0,0\}$. Berdasarkan fungsi tujuan pada Persamaan (1) maka keuntungan yang diperoleh dari perhitungan greedy by profit dengan total berat barang yang diangkut sebesar $15319 \mathrm{Kg}$ yaitu Rp.13952000.

\subsubsection{Greedy by density}

Greedy by density adalah strategi mengurutkan barang-barang berdasarkan rasio terbesar dengan tetap memperhatikan berat barang kemudian dimasukkan satu persatu barang kedalam truk sampai kapasitas truk penuh atau sudah tidak ada lagi yang bisa dimasukkan. Pada perhitungan dengan menggunakan greedy by density barang yang akan dimasukkan kedalam truk yang bernilai 1 yaitu $\left\{x_{1}, x_{2}, x_{3}, x_{4}, x_{5}, x_{6}, x_{7}, x_{8}, x_{9}, x_{10}, x_{11}, x_{12}, x_{13}, x_{14}\right.$, $\left.x_{15}, x_{16}, x_{17}, x_{18}, x_{19}, x_{20}, x_{21}, x_{22}, x_{23}\right\}$ sedangkan untuk $\left\{x_{24}, x_{25}, x_{26}, x_{27}, x_{28}, x_{29}, x_{30},\right\}$ bernilai 0 karena apabila ketiga barang tersebut dimasukkan maka akan melebihi kapasitas truk. Menurut perhitungan greedy by density diperoleh solusi optimal yaitu $X=$ $\{1,1,1,1,1,1,1,1,1,1,1,1,1,1,1,1,1,1,1,1,1,1,1,1,0,0,0,0,0,0,0\}$. Berdasarkan fungsi tujuan pada Persamaan (1) maka keuntungan yang diperoleh dari perhitungan greedy by density dengan total berat barang yang diangkut sebesar $149549 \mathrm{Kg}$ yaitu Rp. 13848000 .

\subsection{Perhitungan Metode Branch and Bound}

Sebelum menerapkan metode branch and bound terlebih dahulu menentukan batas dantzig. Batas dantzig adalah batas akhir barang yang jika semua barangnya dimasukkan maka akan melebihi kapasitas knapsack dan apabila tidak dimasukkan maka knapsack akan bersisa (Supatimah dkk, 2019). Langkah awal dalam menentukan batas dantzig yaitu memasukan barang kedalam knapsack dengan memilih barang dengan memperhatikan rasio dari setiap barang, dan apabila yang memiliki nilai rasio yang sama maka yang dipilih terlebih dahulu yang memiliki keuntungan yang lebih besar . maka didapatkan :

$$
s=\min \left(j: w_{1}+w_{2}+w_{3}+\cdots+w_{24}=15604>15600\right) .
$$

Berdasarkan hasil yang diperoleh sebelumnya dapat dilihat bahwa batas dantzig terletak pada barang $x_{24}$ untuk semua barang yang dimasukkan sebelum batas dantzig benilai 1 yaitu : 
$\left\{x_{1}, x_{2}, x_{3}, x_{4}, x_{5}, x_{6}, x_{7}, x_{8}, x_{9}, x_{10}, x_{11}, x_{12}, x_{13}, x_{14}, x_{15}, x_{16}, x_{17}, x_{18}, x_{19}, x_{20}, x_{21}, x_{22}, x_{23}, x_{24}\right\}$ dan untuk barang yang terletak setelah batas dantig akan bernilai 0 . Setelah dilakukan penentuan batas dantzig makan akan dilakukan perhitungan nilai perbaikan batas yaitu :

$$
x_{24}=\frac{c-\sum_{i=1}^{23} w_{i}}{w_{23}}=\frac{15600-14954}{650}=\frac{323}{325}
$$

Berdasarkan Persamaan (2) dan (3) maka diperoleh solusi optimal yaitu $X=$ $\left\{1,1,1,1,1,1,1,1,1,1,1,1,1,1,1,1,1,1,1,1,1,1,1, \frac{323}{325}, 0,0,0,0,0,0\right\}$ dengan nilai dari $Z$ relaksasi yang didapat dengan menggunakan software Lingo 11.0 yaitu 14171000 . Karena nilai dari $x_{24}$ bernilai pecahan maka perlu dilakukan pencabangan untuk mendapatkan hasil integer. Untuk itu dalam setiap iterasi permasalahan akan dibagi menjadi subpermasalahan yaitu dengan ditambahkan dua kendala untuk setiap iterasi yaitu $x_{i}=0$ dan $x_{i}=1$. Pada pencabangan ini untuk batas atasnya ditentukan berdasarkan hasil dari Z optimal pada program relaksasi sebelumnya yaitu 14171000 sedangankan untuk batas bawah adalah hasil dari solusi sebelum batas dantzig yaitu 13848000 . Pencabangan ini akan terus dilakukan apabila solusi yang dihasilkan pada satu variable bernilai pecahan. Setiap node pencabangannya dapat dilihat pada Gambar 1 dengan didapatkan solusinya sebagai berikut :

a. $\quad$ Pada node 2 batas dantzig berada pada $x_{26}=\frac{173}{200}$ dan diperoleh solusi optimal pada node 2 yaitu: $Z=\left\{1,1,1,1,1,1,1,1,1,1,1,1,1,1,1,1,1,1,1,1,1,1,1,1,0,1, \frac{173}{200}, 0,0,0,0\right\}$, sedangkan untuk node 3 batas dantzig berada pada $x_{23}=\frac{283}{285}$ dengan solusi optimal yang diperoleh yaitu $Z=$ $\left\{1,1,1,1,1,1,1,1,1,1,1,1,1,1,1,1,1,1,1,1,1,1,1, \frac{283}{285}, 1,0,0,0,0,0,0\right\}$.

b. Pada node 4 batas dantzig berada pada $x_{27}=\frac{173}{410}$ dan diperoleh solusi optimal pada node 4 yaitu $Z=\left\{1,1,1,1,1,1,1,1,1,1,1,1,1,1,1,1,1,1,1,1,1,1,1,1,0,1,0, \frac{173}{410}, 0,0,0\right\}$, sedangkan untuk node 5 batas dantzig berada pada $x_{25}=\frac{123}{150}$ dengan solusi optimal yang diperoleh yaitu $Z=$ $\left\{1,1,1,1,1,1,1,1,1,1,1,1,1,1,1,1,1,1,1,1,1,1,1,0,1,0, \frac{123}{150}, 0,0,0,0\right\}$.

c. Pada node 6 batas dantzig berada pada $x_{27}=\frac{173}{410}$ dan diperoleh solusi optimal yaitu $Z=$ $\left\{1,1,1,1,1,1,1,1,1,1,1,1,1,1,1,1,1,1,1,1,1,1,1,1,0,1,0, \frac{173}{410}, 0,0,0\right\}$, sedangkan untuk node 7 batas dantzig berada pada $x_{23}=\frac{258}{285}$ dengan solusi optimal yang diperoleh yaitu $Z=$ $\left\{1,1,1,1,1,1,1,1,1,1,1,1,1,1,1,1,1,1,1,1,1,1,1, \frac{258}{285}, 0,1,1,1,0,0,0\right\}$.

d. Pada node 8 batas dantzig berada pada $x_{29}=\frac{121}{455}$ dan diperoleh solusi optimal yaitu $Z=$ $\left\{1,1,1,1,1,1,1,1,1,1,1,1,1,1,1,1,1,1,1,1,1,1,0,0,1,0,1, \frac{121}{455}, 0\right\}$, sedangkan untuk node 9 batas dantzig berada pada $x_{22}=\frac{54}{341}$ dengan solusi optimal yang diperoleh yaitu $Z=$ $\left\{1,1,1,1,1,1,1,1,1,1,1,1,1,1,1,1,1,1,1,1,1,1, \frac{54}{341}, 1,0,0,1,1,0,0,0\right\}$.

e. Pada node $10, x_{29}$ artinya untuk $x_{30}=1$ akan dimasukkan kedalam truk sehingga semua variable bernilai integer sehingga memperoleh solusi optimal yaitu $Z=$ $\{1,1,1,1,1,1,1,1,1,1,1,1,1,1,1,1,1,1,1,1,1,1,0,0,1,0,1,0,1\}$, sedangkan untuk node 11 batas dantzig berada pada $x_{23}=\frac{118}{285}$ dengan solusi optimal yang diperoleh yaitu $Z=$ $\left\{1,1,1,1,1,1,1,1,1,1,1,1,1,1,1,1,1,1,1,1,1,1, \frac{118}{285}, 0,0,1,10,1,0\right\}$. 


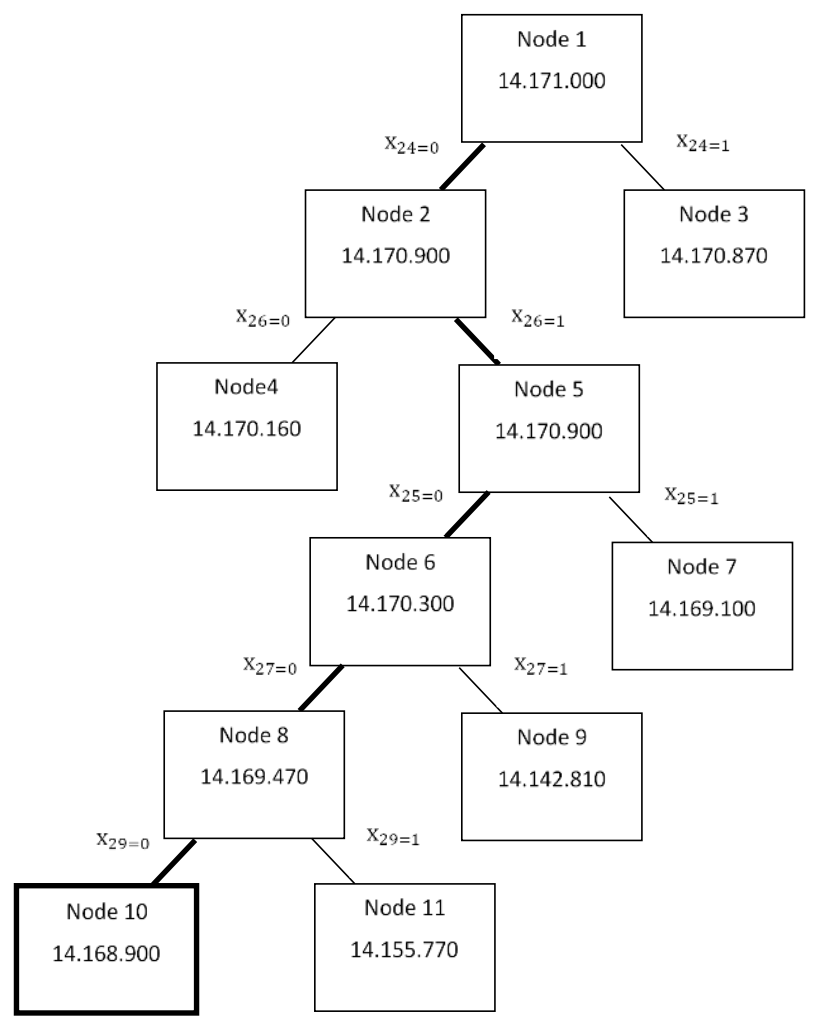

Gambar 1 : Pencabangan Node

\subsection{Rekapitulasi Solusi Optimal}

Setelah dilakukan perhitungan dengan menggunakan algoritma greedydan metode branch and bound di PK. Murni Sanjaya maka diperoleh solusi optimal. Untuk greedy by weight diperoleh hasil optimal sebanyak 27 kayu dimuat dengan total berat $15389 \mathrm{Kg}$ yaitu Rp.12817900, pada greedy by profit solusi yang dihasilkan yaitu sebanyak 23 kayu dimuat diperoleh keuntungan Rp.13952000 dengan total berat $15319 \mathrm{Kg}$, dan greedy by density diperoleh solusi sebanyak 23 kayu dimuat dengan keuntungan yaitu Rp.13952000 dan berat total $14954 \mathrm{Kg}$. Sedangkan untuk solusi optimal dengan menggunakan metode branch and bound yaitu sebanyak 26 jenis kayu yang dimuat dengan keuntungan untuk total berat $15599 \mathrm{Kg}$ yaitu Rp14168900.

Tabel 2 : Rekapitulasi Perbandingan Solusi

\begin{tabular}{|c|c|c|c|c|}
\hline \multirow{2}{*}{$\begin{array}{c}\text { Barang } \\
\text { Ke }\end{array}$} & $\begin{array}{c}\text { Greedy By } \\
\text { Weight }\end{array}$ & $\begin{array}{c}\text { Greedy By } \\
\text { Profit }\end{array}$ & $\begin{array}{c}\text { Greedy By } \\
\text { Density }\end{array}$ & $\begin{array}{c}\text { Branch and } \\
\text { Bound }\end{array}$ \\
\hline$x_{1}$ & 0 & 1 & 1 & 1 \\
\hline$x_{2}$ & 1 & 1 & 1 & 1 \\
\hline$x_{3}$ & 1 & 1 & 1 & 1 \\
\hline
\end{tabular}




\begin{tabular}{|l|l|l|l|l|}
\hline$x_{4}$ & 1 & 1 & 1 & 1 \\
\hline$x_{5}$ & 1 & 1 & 1 & 1 \\
\hline$x_{6}$ & 1 & 1 & 1 & 1 \\
\hline$x_{7}$ & 1 & 1 & 1 & 1 \\
\hline$x_{8}$ & 0 & 1 & 1 & 1 \\
\hline$x_{9}$ & 1 & 1 & 1 & 1 \\
\hline$x_{10}$ & 1 & 1 & 1 & 1 \\
\hline$x_{11}$ & 1 & 1 & 1 & 1 \\
\hline$x_{12}$ & 1 & 1 & 1 & 1 \\
\hline$x_{13}$ & 1 & 1 & 1 & 1 \\
\hline$x_{14}$ & 1 & 1 & 1 & 1 \\
\hline$x_{15}$ & 1 & 1 & 1 & 1 \\
\hline$x_{16}$ & 1 & 1 & 1 & 1 \\
\hline$x_{17}$ & 1 & 1 & 1 & 1 \\
\hline$x_{18}$ & 1 & 1 & 1 & 1 \\
\hline$x_{19}$ & 1 & 1 & 1 & 1 \\
\hline$x_{20}$ & 1 & 1 & 0 & 1 \\
\hline$x_{21}$ & 1 & 1 & 0 & 1 \\
\hline$x_{22}$ & 1 & 0 & 1 & 1 \\
\hline$x_{23}$ & 1 & 0 & 1 & 1 \\
\hline$x_{24}$ & 1 & 0 & 1 & 1 \\
\hline$x_{25}$ & 1 & 0 & 1 & 1 \\
\hline$x_{26}$ & 1 & 1 & 1 & 1 \\
\hline$x_{27}$ & 1 & 1 & 1 & 1 \\
\hline$x_{28}$ & 1 & 1 & 1 & 1 \\
\hline$x_{29}$ & 1 & 1 & 1 & 1 \\
\hline$x_{30}$ & 1 & 1 & 1 & 1 \\
\hline & 1 & 1 & 1 & 1 \\
\hline
\end{tabular}

\section{KESIMPULAN}

Untuk permasalahan knapsack 0-1 di PK. Murni Sanjaya ini dapat dimodelkan kedalam bentuk matematika . Perhitungan solusi optimal dan keuntungan total yang ada di PK. Murni Sanjaya dengan menggunakan algoritma greedy diperoleh hasil yang optimal pada perhitungan greedy by profit untuk keuntungan dengan jumlah berat yaitu $15319 \mathrm{Kg}$ yaitu Rp.13952000. Sedangkan untuk solusi optimal dengan menggunakan metode branch and bound dengan keuntungan untuk jumlah berat $15599 \mathrm{Kg}$ yaitu Rp14168900. Perhitungann solusi optimal yang dihasilkan dengan menggunakan perhitungan branch and bound lebih besar keuntungannya dibandingkan dengan menggunakan algoritma greedy. 


\section{DAFTAR PUSTAKA}

[1]. Abdurrahman Rois, M., Penyelesaian Integer Knapsack Problem Menggunakan Algoritma Greedy, Dynamic Programming, Brute Force dan Genetic DY, DYNAMIC PROGRAMMING, BRUTE FORCE DAN GENETIC, Telematika, 2019, 12(2), pp. 8797. doi: 10.35671/telematika.v12i2.841.

[2]. Ambarwari, A. and Yanto, N. W., Penerapan Algoritma Greedy pada Permasalahan Knapsack untuk Optimasi Pengangkutan Peti Kemas, Research Gate, 2016.

[3]. Ammar, M., Implementasi Algoritma Greedy Dalam Menyelesaikan Knapsack Problem Pada Jasa Pengiriman PT. Citra Van Titipan Kilat (TIKI) Kota Makassar, Axiomath: Jurnal Matematika dan Aplikasinya, 2019, 1(September), pp. 26-32.

[4]. Arista, W. M., Penerapan Algoritma Greedy Dan Dynamic Programming Pada Permasalahan Integer Knapsack. Universitas Jember, 2013, Available at: http://repository.unej.ac.id/handle/123456789/6944.

[5]. Dimyati, T. T. and Dimyati, A., Operation Research: Model-model pengambilan keputusan, Sinar Baru Algensindo, 2018, Bandung.

[6]. Kosasi, S., Penyelesaian Bounded Knapsack Problem menggunakan Dynamic Programming, Jurnal IImiah IImu Komputer, 2013, 8(2), pp. 35-43. Available at: http://ejournals.unmul.ac.id/index.php/JIM/article/view/107.

[7]. Prasetya, A. B., Permasalahan Integer Knapsack dengan Algoritma Dynamic Programming dan Algoritma Branch and Bound, Universitas Jember, 2015, Jember, Available at: http://repository.unej.ac.id/handle/123456789/65320.

[8]. Pratiwi, A., Mulyono and Rochmad, Implementasi Algoritma Branch and Bound Pada 0-1 Knapsack Problem Untuk Mengoptimalkan Muatan Barang, Unnes Journal of Mathematics, 2014, 3(2), pp. 90-96. doi: 10.15294/ujm.v3i2.4302.

[9]. Rachmawati, D. and Candra, A., Implementasi Algoritma Greedy Untuk Menyelesaikan, Saintikom, 2013, 12(3), p. '185-192.

[10]. Sabaruddin, R., Solusi Optimum Minmax 0/1 Knapsack Menggunakan Algoritma Greedy, Evolusi, 2016, 4(2), pp. 76-82. doi: https://doi.org/10.31294/evolusi.v4i2.703.

[11]. Setiawani, S., Metode Relaksasi Lagrange Untuk Menentukan Solusi Program Bilangan Cacah, Majalah IImiah Matematika dan Statistika, 2017, 17(2), pp. 49-60.

[12]. Supatimah, S. S., Farida and Andriani, S., Optimasi Keuntungan dengan Metode Branch and Bound, 2019, 10(1), p. 23. 
[13]. Supriadi, D., Perbandingan Penyelesaian Knapsack Problem Secara Matematika, Kriteria Greedy Dan Algoritma Greedy, Indonesian Journal on Computer and Information Technology, 2016, 1(2), pp. 91-99.

[14]. Supriana, I. W., Optimalisasi Penyelesaian Knapsack Problem Dengan Algoritma Genetika, Lontar Komputer: Jurnal IImiah Teknologi Informasi, 2016, p. 182. doi: 10.24843/LKJITI.2016.v07.i03.p06. 